Okajimas Folia Anat. Jpn., 60(4): $211-218$, October 1983

\title{
Comparative Anatomical Observations on the Tongue of the Insectivora
}

\author{
By \\ Shigeru KOBAYASHI, Taeko SHIMODA and Akitatsu SHIMAMURA \\ Second Department of Oral Anatomy, Kyushu Dental College, \\ Kokurakita-ku, Kitakyushu 803, Japan \\ -Received for Publication, June 9, $1983-$
}

\begin{abstract}
Key words: Insectivora, Tongue, Vallate papilla, Fungiform papilla, Filiform papilla.
Summary: The tongues of the Insectivora; House Musk Shrew (Suncus murinus riukianus), Temminck's Mole (Mogera kobeae), and Furry Snouted Shrew Mole (Dymecodon pilirostris), were observed by lens and scanning electron microscope.

The tongue and lingual apex of the three species were distinct from each other. In House Musk Shrew, the tongue tapered and lingual apex was pointed, in Temminck's Mole rectangular and flat, and in Furry Snouted Shrew Mole elliptical and rounded. On the tongue roots of all of the species, two vallate papillae were observed. Those shapes were different. However, foliate papillae were not observed in all of the species. The fungiform papillae were scattered among the filiform papillae, and their distribution was different. The shape and distribution of filiform papillae were different. On the dorsal tongue, the sulcus terminals, sulcus medianus linguae, and lingual prominence were absent in all the species.

In only the Furry Snouted Shrew Mole's anterior margin were the papillary projections markedly distinct from the lingual papillae of the tongues observed.
\end{abstract}

The tongues of mammals vary according to morphology of the species. Food habits and strain are considered to be the reasons. General descriptions of the tongues of mammals have been reviewed by Münch (1896), Sonntag (1920, 1925), Stadtmüller (1938), Keaster (1940), and Bradley (1971). In particular, Sonntag (1920) reported on the vallate, foliate, fungiform, and filiform papillae; morphological variations by the species; and differences of the number of vallate papillae. Despite a number of reports made to date, relatively few reports have been made on the tongue of Insectivora; Tuckerman (1890), Münch (1896), Sonntag (1923), and Lawler (1937). They clarified the variations in morphology not only of the tongue but also of the lingual papillae.

In this paper, the morphological varia- tions using scanning electron microscope of Insectivora's tongue are described, and compared with the three species.

\section{Materials and Methods}

The authors have had an opportunity to investigate the tongue of three species of Insectivora: House Musk Shrew (Suncus murinus riukiuanus), Temminck's Mole (Mogera kobeae), and Furry Snouted Shrew Mole (Dymecodon pilirostris). Two House Musk Shrews and two Temminck's Mole were obtained from Zoological Laboratory, Kyushu University, Fukuoka. Two Furry Snouted Shrew Moles were obtained from National Science Museum, Tokyo.

The mammals were fixed with $10 \%$ neutral formaldehyde. The tongues were 
separated from each animal, then fixed with $10 \%$ neutral formaldehyde with ethanol, dried by the critical point method, and coated with gold palladium to examine under a JSM-25 scanning electron microscope at $20 \mathrm{kV}$ of accelerating voltage.

\section{Observations}

In this paper, the upper surface of tongue is divided into several parts as shown in Fig. 1.

\section{A) The Tongue of House Musk Shrew}

The tongue tapers to, about $20 \mathrm{~mm}$ in length, (approximately $15 \mathrm{~mm}$ in the oral part and $5 \mathrm{~mm}$ in the pharyngeal part) and about $4.5 \mathrm{~mm}$ in width. The lingual apex is pointed. The anterior free part is about 9 $\mathrm{mm}$. The sulcus terminals, sulcus median linguae, foramen linguae, and lingual prominence were absent. (Fig. 2-a) Three types of papillae are present on the dorsal surface of the tongue; the circumvallate, fungiform, and filiform papillae.

The House Musk Shrew has a pair of circumvallate papillae which are located on the lingual root. The papillae are oval in shape, and are surrounded by a trench and by a clear vallum. The summit of the circumvallate papillae are covered with many small secondary papillae. (Fig. 3)

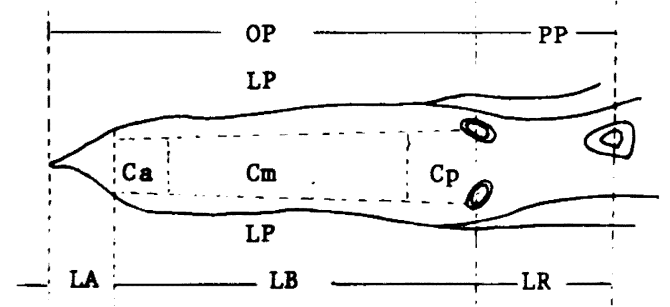

Fig. 1. Schematic diagram of the chief regions on the dorsal view of the tongue. OP: Oral Part, PP: Pharyngeal Part, LP: Lateral Part, LA: Lingeal Apex, Ca: Anterior Central Part, $\mathrm{Cm}$ : Middle Central Part, Cp: Posterior Central Part, LB: Lingual Body, LR: Lingual Root.
Foliate papillae are not visible.

The fungiform papillae exist on the oral part of the dorsum except for the midcentral part, and the lateral border. They are hemispherical or pedunculated, and their surfaces are smooth.

The filiform papillae covered the oral part almost completely and the anterior pharyngeal part partially. These are labiatelike papillae with secondary papillae, and bifid or trifid shaped papillae. (Fig. 9)

The lingual glands open into the nonpapillae area in the pharyngeal part. (Fig. 3)

B) The Tongue of Temminck's Mole

The tongue is rectangular, about $25 \mathrm{~mm}$ in length, (approximately $19 \mathrm{~mm}$ in the oral part and $6 \mathrm{~mm}$ in the pharyngeal part)
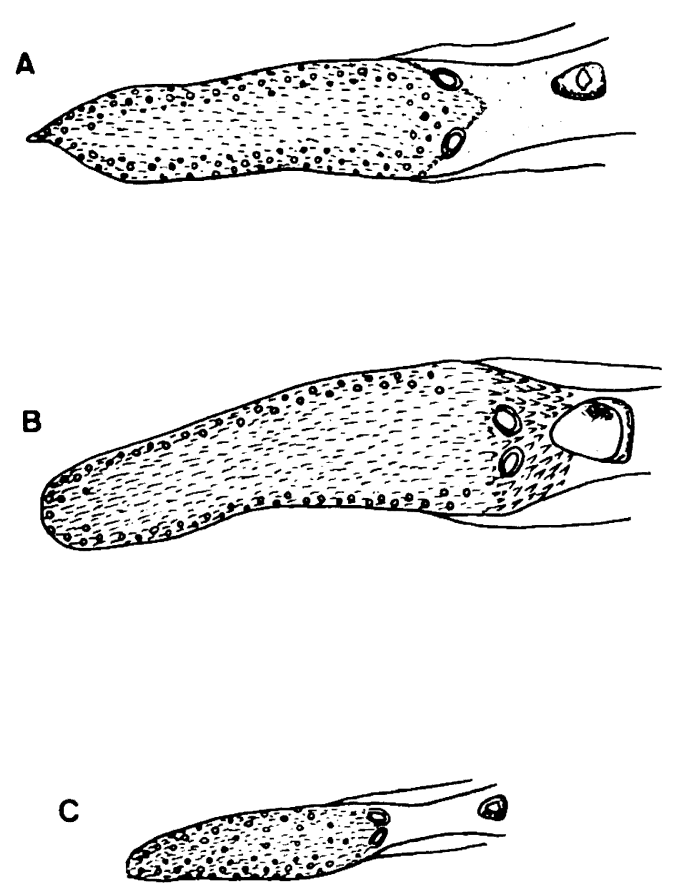

Fig. 2. Dorsal view of the Insectivora tongue.

A) House Musk Shrew (Suncus murinus riukiuanus)

B) Temminck's Mole (Mogera kobeae)

C) Furry Snouted Shrew Mole (Dy. mecodon pilirostris)

Drawings show the differences of the species' tongue. 
and about $5.5 \mathrm{~mm}$ in width. The lingual apex is flat. The anterior free part is about $11.4 \mathrm{~mm}$ in length. The sulcus terminals, sulcus median linguae, foramen liguae, and lingual prominence are absent. (Fig. 2-b)

A pair of circumvallate papillae are observed on the posterior part. They are elliptical in shape, and surrounded by a trench, and by a clear and smooth vallum. Their summits are covered with many small secondary papillae. (Fig. 4)

Foliate papillae was not visible.

Fungiform papillae exist on the sides of the dorsum, and scanty on the apex. The papillae are hemispherical with smooth surfaces.

Filiform papillae are present the dorsal and root of tongue almost completely and differ in morphology by their location, and apical portions which are generally bent toward the posterior direction. All of the anterior half of the tongue is covered with labiate-like papillae. (Fig. 10) On the posterior half of the tongue are so-called filiform papillae. On the pharyngeal part of the tongue are conical papillae.

C) The Tongue of Furry Snouted Shrew

The tongue is elliptical about $13.5 \mathrm{~mm}$ in length, (approximately $9.5 \mathrm{~mm}$ in the oral part $4 \mathrm{~mm}$ in the pharyngeal part) and about $2.5 \mathrm{~mm}$ in width. The lingual apex is rounded with the papillary projections observed at the anterior margin. (Fig. 7) The anterior free part is about $5.7 \mathrm{~mm}$. The sulcus terminals, sulcus median linguae, foramen linguae, and lingual prominence are absent. (Fig. 2-c)

A pair of circumvallate papillae are observed on the posterior part. They are elliptical in shape, and surrounded by a trench, and by a clear and smooth vallum. Their summits are covered with several troughs and some small secondary papillae. (Fig. 5)

Foliate papillae are not visible.
Fungiform papillae exist on the sides of the dorsum and the central parts, but are absent on the apex and the pharyngeal parts.

Filiform papillae, labiate-like are present on the oral part, and absent around the papillary projections and on the pharyngeal part. (Fig. 7)

\section{Discussion}

Insectivora are the smallest and most active of mammals. They are chiefly insects eaters, but some also feed on other small mammals. They are at least partly nocturnal. This group shows generally primitive characteristics of the placental mammals.

According to Sonntag, (1925) the primitive mammalian tongue would have the following characteristics:

1) They are small in size.

2) There are three circumvallate papillae positioned in a triangle with the apex directed backwards. This characteristic has persisted in members of most Orders.

3) Lateral organs (foliate papillae) has not developed.

4) Fungiform papillae are small and scanty, and are not aggregated in an apical cluster.

5) The conical papillae are not aggregated into a large cluster on the apex of the tongue.

According to Sonntag, (1923) the tongues of the Insectivora are very primitive. Their mechanical (filiform) papillae are simple, their gustatory (vallate, foliate, and fungiform) papillae are few. Also, there are three circumvallate papillae in Centetidae, Solenodontidae, and two in Talpidae. In Erinacedidae and Soricidae there are two or three papillae.

It is obvious that the tongues of the present three species has two circumvallate 
papillae. However, there are some differences among their structures; In House Musk Shrew and Temminck's Mole, the shapes of the papillae are oval, while in Furry Snouted Shrew Mole, they are elliptical.

In this study, no foliate papillae are visible. Histological examination may be necessary to prove that there are foliate papillae.

Fungiform papillae are scanty on the oral part of the dorsal tongue, but they differ greatly in structure, number, and arrangement in each species. In House Musk Shrew and Temminck's Mole, they are absent the central part, and also on the apex part of Furry Snouted Shrew Mole.

Filiform papillae are the most numerous of all lingual papillae in these mammals. They vary in size, structure, and arrangement. In House Musk Mole and Furry Snouted Shrew Mole, the papillae are present on the oral part and absent on the pharyngeal part, while in Temminck's Mole papillae are present on the oral and pharyngeal parts. The papillae of Insectivora, as compared with Rodentia, (Kutuzov \& Sicher, 1951) are far more varied. However, compared with Chiroptera, (Kobayashi \& Shimamura, 1982) they are far less complex.

The tongue and lingual apex are distinct from each others. In House Musk Shrew, they are tapered and pointed, in Temminck's Mole they are rectangular and flat, and in Furry Snouted Shrew Mole they are tapered and rounded.

Only in Furry Snouted Shrew Mole, the papillary projections, which are markedly distinct from the lingual papillae of the general tongue, observe at the anterior margin. These papillae are also seen in fetal and young stages of some species of dolphins. (Yamasaki et al., 1978)

As described above, the tongue and the lingual papillae of Insectivora showed considerable differences in morphology and location. However, whether these are due to food habit and/or strain and others, we should be study further.

\section{Acknowledgements}

The authors would like to express their most sincere thanks to associate Professor Shiraishi, S. an Dr. Mōri, T. Zoological Laboratory, Kyushu University, Fukuoka, and Dr. Yoshiyuki, M., National Science Museum, Tokyo, who supplied the tongues of Insectivora used in this study.

\section{References}

1) Bradley, R. M.: Tongue topography. In Beidler, L. M. (Ed.), Handbook of sensory physiology. 4. Chemical senses. 1-30, SpringerVerlag, Berlin, Heidelberg, and New York, 1971.

2) Keaster, J.: Studies on the anatomy and physiology of the tongue. Laryngoscope. 50: 222-258, 1940.

3) Kobayashi, S. and Shimamura, A.: Comparative anatomical observations of the tongue of the Japanese long-fingered bats, Miniopterus schreibersi fuliginosus. Okajimas Folia Anatomica Japonica. 58: 923-932, 1982.

4) Kutuzov, H. and Sicher, H.: The filiform and the conical papillae of the tongue in the white rat. Anat. Rec. 110: 275-288, 1951.

5) Lawler, A. C.: Studies on the sensory structure of the proboscis and tongue of the ground mole. [Scalopus aquaticus $(L)]$. Contr. Biol. Lab. Catholic Univ. Amer. 23: 1-52, 1937. cit. by Bradley, R. M.

6) Münch, F.: Die Topographic der Papillen der Zunge des Menschen und Saugetiere. Schwalber Morphol. Arbeit. 6: 605-690, 1896.

7) Sonntag, C. F.: The comparative anatomy of the tongue of mammalia. I. General description of the tongue. Proc. Zool. Soc. Lond. 115-129, 1920.

8) Sonntag, C. F.: The comparative anatomy of the tongue of mammalia. IX. Edentata, Dermoptera, and Insectivora. Proc. Zool. Soc. Lond. 515-529, 1923. 
9) Sonntag, C. F.: The comparative anatomy of the tongue of mammalia. XII. Summary, classification and phylogeny. Proc. Zool. Soc. Lond. 701-762, 1925.

10) Stadtmüller, F.: Zunge, Mundhölenboden. In Bolk, L., Göppert, E., Kallius, E. und Lubosch, W. (Edn.) Handbuch der vergleichenden Anatomie der Wirbeltiere. Bd. 5. Urban und Schwarzenberg, Berlin und Wien. 955-1010, 1938.
11) Tuckerman, F.: On the gustatory organs of some of the mammalia. J. Morph. 4: 151-191, 1890.

12) Yamasaki, F., Komatsu, S. and Kamiya, T.: Papillary projections at the lingual margin in the striped dolphin, Stenella coeruleoalba, with special reference to their development and regression. J. Morph. 157: 33-48, 1978. 


\section{Explanation of Figures}

\section{Plate I}

Figs. 3-5. Scanning electron micrograph of a pair of vallate papillae of the Insectivora tongue.

Fig. 3. House Musk Shrew, arrow: Opening of the mucous gland.

Fig. 4. Temminck's Mole.

Fig. 5. Furry Snouted Shrew Mole

Figs. 6 and 7. Scanning electron micrograph of lingual apex of the Insectivora.

Fig. 6. Pointed type in House Musk Shrew.

Fig. 7. Notch type and papillary projections in Furry Snouted Shrew Mole.

Fig. 8. Peduncular shaped fungiform papillae in House Musk Shrew.

Figs. 9 and 10. Filiform papillae vary by the species and location.

Fig. 9. Bifid papillae on the mid-central part of the tongue of House Musk Shrew.

Fig. 10. Labiate-like papillae on the mid-central part of the tongue of Temminck's Mole. 


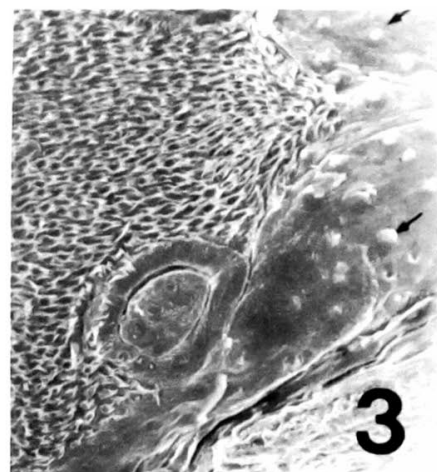

Plate I
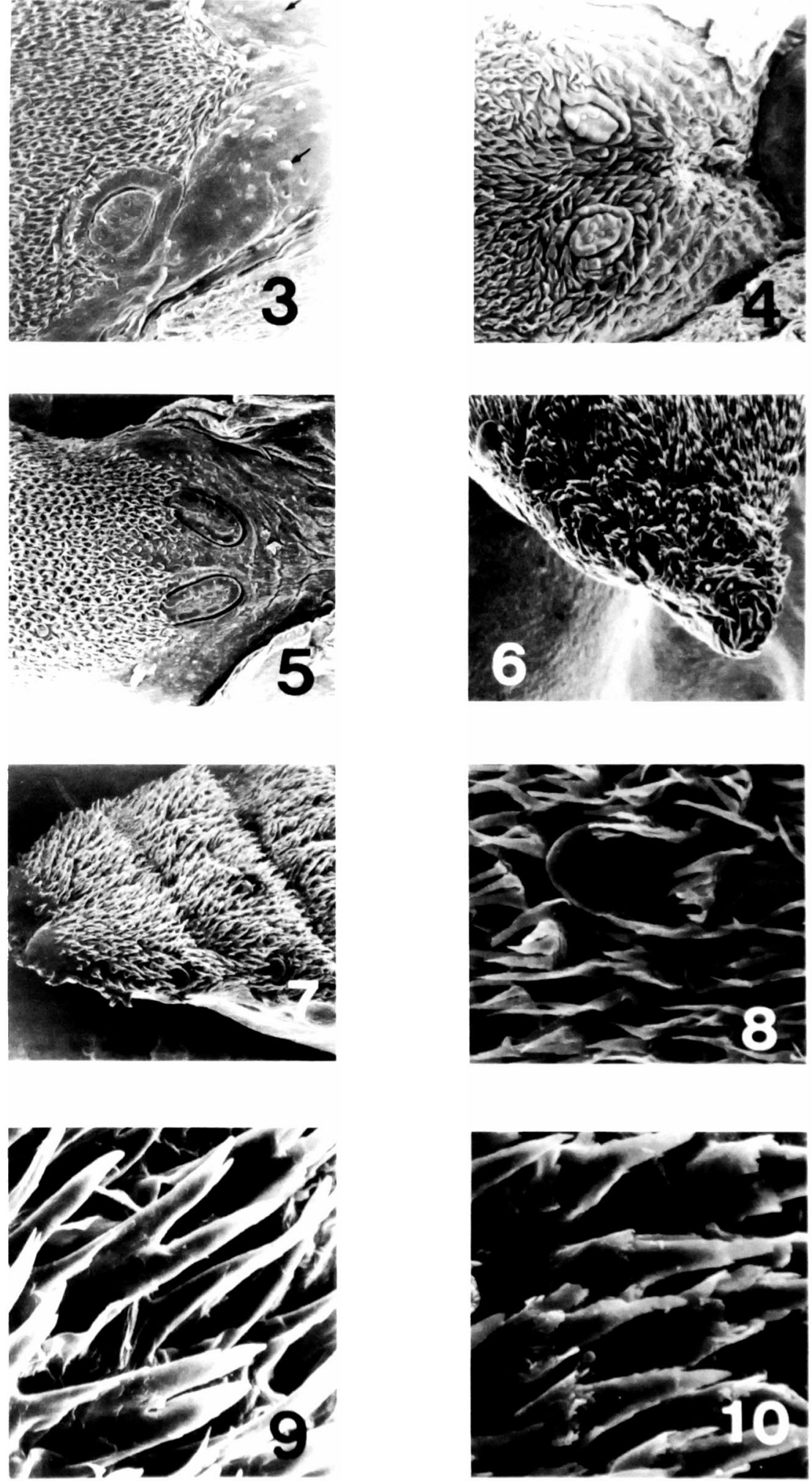